\title{
PRESENCIA Y FORTUNA DE LOS HOMBRES DE NEGOCIOS GENOVESES DURANTE LA CRISIS HISPANA DE 1640
}

por

\author{
CARMEN SANZ AYÁN \\ Universidad Complutense
}

RESUMEN: El protagonismo de los financieros genoveses en los tratos con la Monarquía Hispánica bajo Felipe II, Felipe III y hasta la suspensión de pagos de 1627 con Felipe $I V$, fue un becho evidente. En la década de 1630, aunque no ejercieron el monopolio de antes por la irrupción en el de panorama financiero de los judeoconversos portugueses, continuaron siendo mayoritarios en las negociaciones de provisiones generales. Sin embargo, la especial coyuntura que la Monarquía atravesó durante la década de 1640 modificó su presencia y actitud. Este artículo analiza su actuación en aquellos momentos difíciles, que fue de retirada a partir de aquel año y hasta la caída de Olivares, de una tímida reaparición tras el relevo del valido y de un efimero protagonismo después de la suspensión de pagos de 1648, ya que lo ofrecido por la corona para recompensar sus servicios financieros no resultó suficientemente atractivo desde un punto de vista económico y, además, suponía un coste social elevado para las familias genovesas de bombres de negocios, integradas en las redes aristocráticas castellanas.

Palabras Clave: Génova. Monarquía Hispánica. Banqueros. Sistema financiero. Crisis del siglo XVII. Aristocracia. Redes mercantiles.

ABSTRACT: The prominence of Genoese financiers in making deals with the Spanish Monarchy during the reigns of Philip II, Pbilip III and -until 1627, with the suspension of payment - Pbilip IV, was clear. During the 1630s, although they could not exercise their erstwhile monopoly as Portuguese conversos burst into the financial arena, they remained dominant in negotiations of general provisions. However, the peculiar state of affairs for the Spanish Monarchy in the 1640s did alter their standing and attitudes. This article analyses their conduct during these hard years. This involved retreat from the events of 1640 until the fall of Olivares, followed by a timid reappearance when. the favourite was replaced, and a short-lived prominence after the suspension of payments in 1648. This prominence was 


\begin{abstract}
thwarted at once, for the crown's offer to compensate their financial services was not appealing enough in economic terms and posed too high a social cost for Genoese merchant families, integrated into the Castilian aristocratic circles.
\end{abstract}

KEY WORDS: Genoa. Hispanic Monarchy. Bankers. Financial System. Seventeenth-century crisis. Aristocracy. Merchant networks.

En 1631 Castillo Solórzano publicaba una obra, Las Harpías en Madrid, conformada por cuatro narraciones cortas que relataban las andanzas de unas pícaras sevillanas en la Corte. El protagonista del segundo relato era un asentista genovés que, retratado como un recalcitrante avaro, resultaba engañado por las malas aunque inteligentes- artes de aquellas falsas damas que, tras amañar una letra de cambio supuestamente firmada por un reputado banquero genovés afincado en Sevilla (Carlos Grimaldo), conseguían estafar al avisado asentista más de cuatro mil reales de plata. Una cantidad que el genovés pensó que entregaba sin daño de su dinero y por vía de empréstito ${ }^{1}$, sobre un caudal fijo que importaba el doble de lo prestado según rezaba en el falso documento bancario.

El relato de Solórzano, elaborado en función de una creciente demanda de este tipo de obras de entretenimiento ${ }^{2}$, da indicios de lo familiares que podían resultar para un lector conceptos como asiento o asentistas en las primeras décadas del siglo XVII hispano. Que en el cuentecillo se hablara con soltura de las idas y venidas de un negociante ligur al Consejo de Hacienda para concluir un asiento, era una prueba de la cotidianeidad con la que estos hechos sucedían y probablemente es también la razón por la que la figura de un asentista genovés podía convertirse en un estereotipo literario que sirviera para divertir, entretener o incluso criticar superficialmente aquellas situaciones. La omnipresencia de los genoveses en la vida financiera de la Monarquía Hispánica durante los reinados de Felipe II y Felipe III $^{3}$ era, por tanto, un hecho evidente no sólo en las cuentas del Consejo de Hacienda sino a los ojos de los súbditos.

Cuando Felipe IV llegó al trono los genoveses dominaban casi con exclusividad las esferas más altas del mercado de capitales y proporcionaban la mayor parte de los fondos que demandaba la Monarquía. Como es sabido, basaron su predominio financiero en el control de las remesas de Indias, en los reembolsos producidos por la venta de lana peninsular, cochinilla americana y otros géne-

1 La edición utilizada ha sido: DE Castullo Solórzano, A.: Las harpías en Madrid. Madrid, Clásicos Castalia, 1985. Edición de Pablo Jauralde Pou. El relato referido es el titulado Estafa Segunda, pp. 100 a 131 .

2 Sobre la fortuna de este género literario vid. RodríGUEZ, E.: Novela corta marginada del siglo XVII español. Valencia, Universidad de Valencia, 1979. y REY HAZAS, A.: «Introducción a la novela del Siglo de Oro» en Edad de Oro, I. Madrid, 1982, pp. 65-105.

3 Para la primera de todas estas operaciones vid. WILLIAMS, P.: «Philiph III and the restoration of Spanish government 1598-1603» en The English Historical Review, LXXXVIII, 1973, pp. 766 y ss.

Hispania, LXV/1, núm. 219 (2005) 91-114 
ros en los territorios italianos ${ }^{4} \mathrm{y}$, sobre todo, en la redistribución de la deuda pública emitida por la Corona mediante los sucesivos procesos de crecimientos de juros decididos tras las suspensiones de pagos que gestionaron y fiscalizaron consiguiendo grandes beneficios 5 .

Sin embargo, a partir de la reanudación de la guerra con las Provincias Unidas, demostraron que no podían atender con la exclusividad de años atrás los adelantos necesarios para sufragar los gastos de guerra ${ }^{6}$. La crisis de las ferias de Besançon y de Piacenza desde las que los banqueros de la República desplegaban su red internacional de pagos mediante un complejo sistema de letras de cambio, entorpeció la capacidad operativa de sus hombres de negocios. Todo se complicó aún más tras la suspensión de consignaciones de 1627. Con ella su estrella empezó a declinar ${ }^{7}$ porque, ante su incredulidad, les había salido un grupo competidor sólido; "gente piu bassa» ${ }^{8}$ de origen portugués, según la personal apreciación de sus vecinos venecianos, que había "crecido» en los negocios internacionales casi sin que se dieran cuenta.

Transcurrido el primer cuarto del siglo XVII, el panorama político de fondo con el que tuvieron que operar los financieros ligures también cambió respecto al que disfrutaron en periodos anteriores. El Conde Duque de Olivares a partir de 1626 acometió una «limpieza» entre el personal del Consejo de Hacienda, porque entendía que varios de sus consejeros se hallaban implicados en una estrecha relación de intereses con los hombres de negocios genoveses 9 . Una relación que se consideraba había sido muy perjudicial para la hacienda de la Monarquía. Además, el mercado de la deuda pública que ellos controlaban desde el siglo XVI,

4 Ruiz Martín, F.: Pequeño capitalismo, gran capitalismo. Simón Ruiz y sus negocios en Florencia. Barcelona, Crítica, 1990. pp. 110 y ss.

5 Un modo indirecto pero bastante fiable para valorar las ganancias de los genoveses a través de la Diputación del Medio General son las cifras de acuñaciones de plata en Génova que da Felloni. De 1601 a 1607 la media anual de acuñación fue de 200.000 escudos pero entre 1608 y 1614 ascendió a 2.000.000. FelLONI, G.: «Profilo economico della moneta genovese del 1139 al 1814» en Le Monete Genovesi. Storia, arte e economía nelle monete di Genova dal 1319 al 1814. Génova, 1971, pp. 320-321.

6 Está documentado que en 1626 los hombres de negocios portugueses afincados en Amberes proporcionaban capital a los «paguistas» genoveses que habían contraído obligaciones con la pagaduría general del Ejército de Flandes, Es decir, que indirectamente, a través de los genoveses, el capital portugués ya había entrado en el negocio de abastecimiento del ejército de Flandes. En Esteban Estríngana, A.: Guerra y finanzas en los Países Bajos católicos de Farnesio a Spinola (15921630). Madrid, Ediciones del Laberinto, 2002. p. 226.

7 MAIXe AlTES, J.C.: «La Colonia genovesa en Cataluña en los siglos XVI y XVII» en Primer Congrés d'Historia Moderna de Catalunya, Barcelona, Universidad de Barcelona, 1984. vol. 1, pp.523533 señala que sus dificultades se acrecentaron a partir de 1640.

8 Ruiz Martin, F. :, Lettres marchandes échangées entre Florence et Medina del Campo. París, S.E.V.P.E.N. Armand Colin, 1965, capitulo I, p. XXXIX.

Esto argumentaba el embajador de Venecia en Madrid en su informe a la Signoría en fecha tan temprana como 1573. En SAPORI, A., Il mercante italiano nel Medievo. Quatre conferences tenuete all E'cole pratique des Hautes Études, Milán. 1983, p. 80.

9 ElliotT, J.H.: Richelieu y Olivares. Barcelona, Crítica, 1984, p. 94. 
empezó a mostrar signos de saturación ya que los juros emitidos para dar satisfacción a los banqueros decretados no podrían colocarse en el mercado, según sus previsiones, hasta mucho tiempo después y a un precio menor que el de su valor nominal ${ }^{10}$. A ello debía añadirse que el problema de la inflación del vellón mostraba abiertamente sus nefastos resultados y los banqueros genoveses históricos, Centurión, Spínola o Grimaldo-, parecían resistirse a aceptar la esencia del negocio que para ellos suponía la irrupción de esta nueva variable en las actividades financieras con la Monarquía; un negocio que sí captaron con extraordinaria habilidad los banqueros judeoconversos de origen portugués ${ }^{11}$ y algunos otros genoveses menos «tradicionales» en sus usos como los Piquinoti, por ejemplo.

Aún así, durante la década de los treinta, los financieros ligures siguieron protagonizando la vida financiera de la Monarquía y, aunque no ejercieron el monopolio de años anteriores por la irrupción del capital luso, su presencia siguió siendo mayoritaria en las negociaciones de provisiones generales.

Sin embargo, la especial coyuntura que la Monarquía Hispánica atravesó durante la década de 1640, modificó una vez más su presencia y actitud en los negocios que mantenían con la ella. El contenido de estas páginas se adentra en el análisis de su actuación en aquellos difíciles años, en la posición que adoptaron ante la caída de Olivares y en la actitud que mantuvieron inmediatamente después, tanto antes como tras la suspensión de pagos de 1647.

\section{LOS FINANCIEROS GENOVESES Y LA CRISIS DE 1640 ANTES DE LA CAÍDA DE OLIVARES}

El análisis del crédito de la Monarquía en los años cuarenta ha sido abordado por varios estudiosos que de manera directa o colateral han reparado en la importancia de conocer esta variable a la hora de entender las dificultades financieras por las que atravesó Felipe IV en aquella extrema coyuntura. El trabajo pionero de Domínguez Ortiz ${ }^{12}$ sobre la Hacienda de Felipe IV, el de Boyajian ${ }^{13}$ y los banqueros portugueses del reinado, el de Álvarez Nogal ${ }^{14}$ acerca

10 Como mucho se calculaba venderlos por un $75 \%$ de su valor. Sobre la huida de los genoveses en las negociaciones con vellón vid.: GELABERT, J.E.: "La evolución del gasto de la Monarquía Hispánica entre 1598 y 1650. Asientos de Felipe III y de Felipe IV» Studia Historica, 18, 1998, pp. 265-297, p. 279.

11 Conviene recordar que otros genoveses, (Grillo, Piquinoti, Lomelín), de origen menos antiguo en las actividades financieras con la Monarquía, sí supieron adaptarse a las nuevas condiciones e incluso fundaron compañías mixtas en asociación con banqueros de origen judeoconverso portugués, algunas de mucha importancia en la segunda mitad del siglo XVII.

12 Dominguez Ortiz, A.: Politica y Hacienda de Felipe IV. Madrid, Ed. Pegaso, 1983 (2a ed.)

13 BOYAJIAN, J.C.:Portuguese bankers at the court of Spain 1626-1650. New Brunswick, 1983.

14 Alvarez Nogal, C.: El crédito de la Monarquia Hispánica en el reinado de Felipe IV. Avila, Junta de Castilla y León. 1997.

Hispania, LXV/1, núm. 219 (2005) 91-114 
del peso de las remesas de Indias en las negociaciones de los banqueros con la Corona, el discurso de entrada a la Real Academia de la Historia de Ruiz Martín $^{15}$, el estudio sobre la financiación de la Guerra de Flandes de Alberto Mar$\cos ^{16}$ y las dos aportaciones más recientes de J. E. Gelabert ${ }^{17}$ que abordan la fiscalidad de Castilla en la primera mitad del siglo XVII, configuran una excelente base de partida. Quedaba, sin embargo ${ }^{18}$, incluir en esos análisis las provisiones que se efectuaron en vellón ${ }^{19}$ ya que hasta ahora sólo se ha puesto especial énfasis en las que se materializaron en plata por resultar indicativas de las disponibilidades crediticias de la Monarquía fuera de Castilla.

Los hombres de negocios que operaron en esta década se convirtieron en grandes receptores de vellón. Una parte importante de los préstamos que ofrecieron a la Corona se reintegraron junto con sus intereses en esta moneda y esto fue así desde los inicios del siglo XVII ${ }^{20}$. Aquel fenómeno se intensificó años más tarde aunque hasta hoy no existen investigaciones exhaustivas al respecto en el terreno de la historia monetaria. Esta omnipresencia del vellón tuvo su traducción directa en la calidad de los préstamos que recibió la Corona y en la capacidad crediticia de muchos financieros a medio plazo.

Obviar la evolución del crédito en vellón podía distorsionar el análisis de las operaciones financieras globales llevadas a cabo por la Monarquía y por esta razón era necesario revisar de nuevo la contabilidad de los asientos firmados en los años cuarenta, aunque una vez conocidas y separadas las cuentas, el vellón debe deflactarse según los premios de la plata que corrían anualmente, para tener una idea del volumen global del crédito que cada financiero soportaba y que la Monarquía pudo conseguir.

15 Ruiz Martín, F.: las finanzas de la Monarquía en tiempos de Felipe IV (1621-1665). Madrid, R.A.H., 1990.

16 Marcos Martín, A.: «España y Flandes (1618-1648). La financiación de la Guerra en ALCalÁ Zamora, J. y Berenguer, E. (Eds.): Calderón de la Barca y la España del Barroco. Madrid, 2001, vol. II, pp. 15-39.

17 Gelabert, J.E. : La bolsa del Rey. Rey, reino y fisco en Castilla (1598-1648). Barcelona, Crítica, 1997. Y Gelabert, J.: Castilla convulsa (1631-1652). Madrid, Marcial Pons, 2001.

18 En realidad sólo se conocía hasta hoy la evolución global del crédito negociado por la Monarquía en plata a partir de los datos que para 1639-1650 ofrecí al profesor Gelabert para que los publicara junto con los suyos en GELABERT, J.E. en «La evolución del gasto de la Monarquía Hispánica entre 1598 y 1650» en Studia Historica vol. 18, 1998. pp. 265-297.

19 Obviamente no podemos saber si nuestras fuentes tienen todos los asientos contratados a lo largo del periodo porque no existen otras fuentes alternativas que permitan contrastarlo. También soy consciente de que, obviamente el crédito «en vellón» es de peor calidad que el que se obtiene en plata

20 El 28\% del vellón que salió de las cecas castellanas en las operaciones de acuñación y resello decretadas en 1602 y 1603 fue a para a manos de los asentistas de modo directo. Vid. García GUERRA, E.M.: Las acuñaciones de moneda de vellón en Castilla durante el siglo XVII (1594-1665). Tesis Doctoral inédita. Madrid. Universidad Complutense, 1997. p. 567.

Hispania, LXV/1, núm. 219 (2005) 91-114 
Los diez años que van de 1639 a 1649 (Gráfico 1) experimentaron un cambio de tendencia significativo en la evolución del crédito. Si entre 1639 y 1642 éste osciló alrededor de los 9 millones de escudos, - teniendo en cuenta las provisiones en vellón convenientemente deflactadas a plata -, a partir de 1643 y hasta 1645 se situó entorno a los 6 millones; por encima de esa cifra en 1643 y 1645 y por debajo en 1644 .

Finalmente, después de haber negociado asientos que oscilaron alrededor de los 6 millones, la tendencia tras la suspensión de pagos de 1647 fue la de situarse entre los cinco y cuatro millones lo que significaba que, en una franja temporal de diez años, la capacidad crediticia de la Monarquía descendió en un 58\%.

\section{GRÁFICO 1}

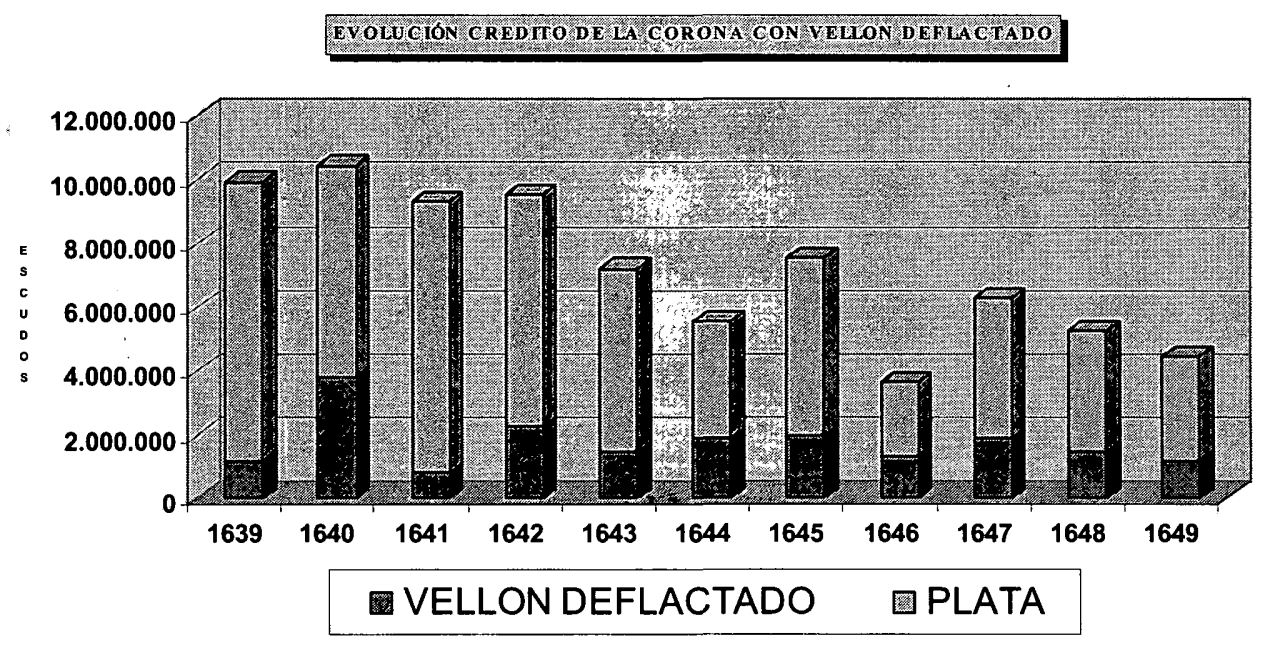

Fuentes: A.G.S. Contadurías Generales legs. 134, 135, 136, 137, 138,139, 140,141, 142, 143.

Teniendo en cuenta estos datos globales, en 1639 siete eran los hombres de negocios que el Consejo de Hacienda consideraba los pilares del sistema de asientos; cuatro portugueses y tres genoveses. (Grafico 2). La Casa de Carlos Strata dominaba mientras a la zaga aparecían los que se convertirán en los principales financieros de la Monarquía en los años cuarenta, Duarte Fernández y, sobre todo, Jorge de Paz Silveira. 
GRÁFICO 2: PRINCIPALES ASENTISTAS (1639)

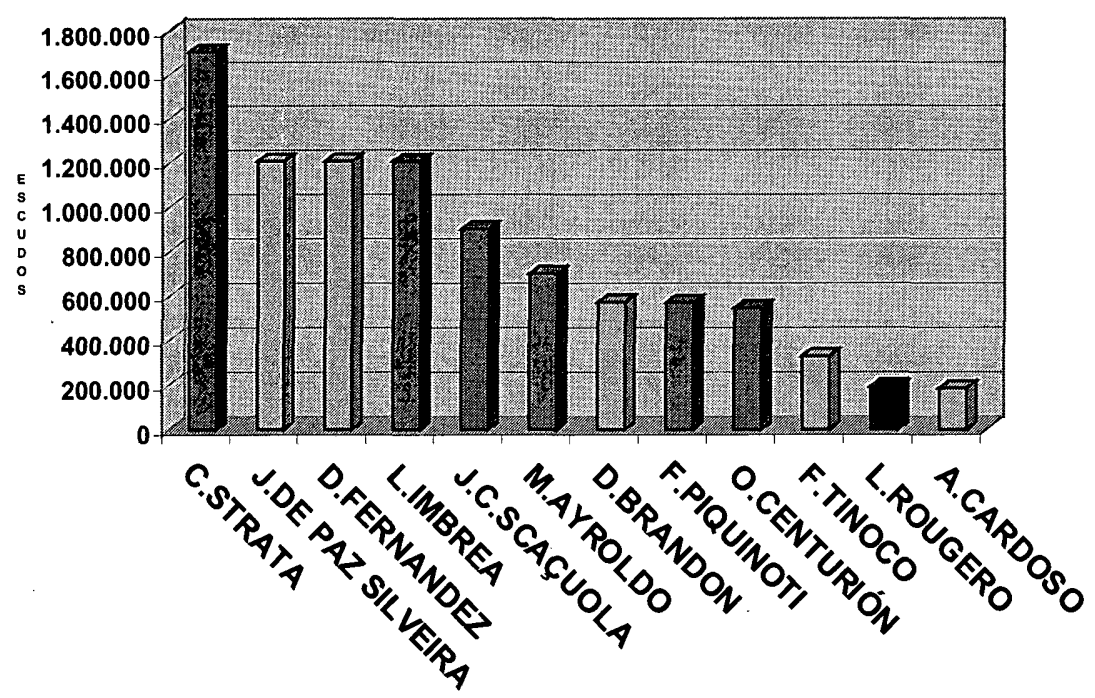

El panorama cambió sustancialmente al año siguiente (gráfico 3).

GRÁFICO 3: PRINCIPALES ASENTISTAS (1640)

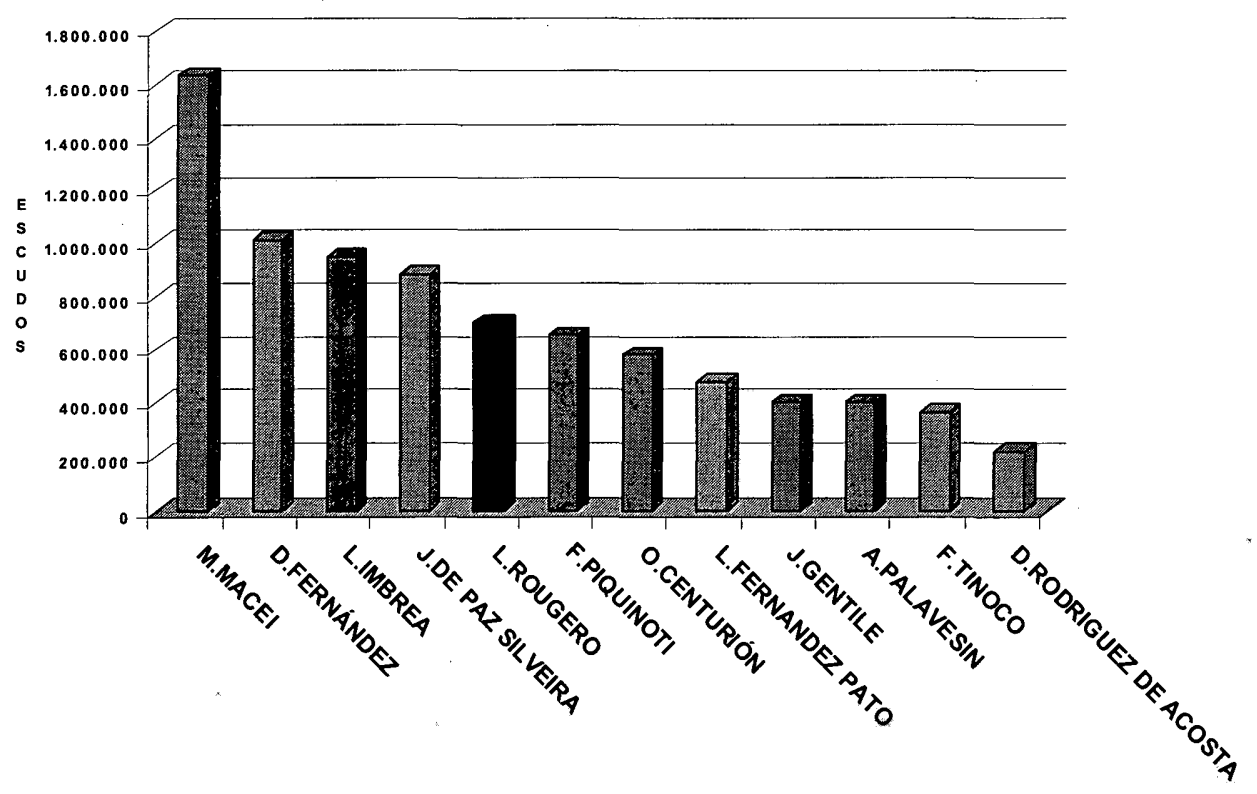


A pesar de las difíciles circunstancias, en 1640 hubo hombres de negocios dispuestos a asumir las provisiones generales en las que, por primera vez, los genoveses quedaban relegados a un segundo término. Las novedades de la aparición del Monte de Piedad de Florencia personificado en el senador Maceo Macei o en el consorcio de flamencos encabezado por Luis Rugero Clarisse serán estudiadas en otro lugar. Lo significativo para este análisis es la reducción de la presencia de los genoveses.

En 1641, tras el estallido de las dos sublevaciones periféricas, por primera vez, tres hombres de negocios portugueses Jorge de Paz Silveira, Duarte Fernández y Fernando Tinoco, heredero de la casa de Manuel de Paz, encabezaron las negociaciones (gráfico 4). A partir de este año los términos se invirtieron definitivamente y los lusos pasaron a ser el grupo puntero en las provisiones generales.

\section{GRÁFICO 4: PRINCIPALES ASENTISTAS (1641)}

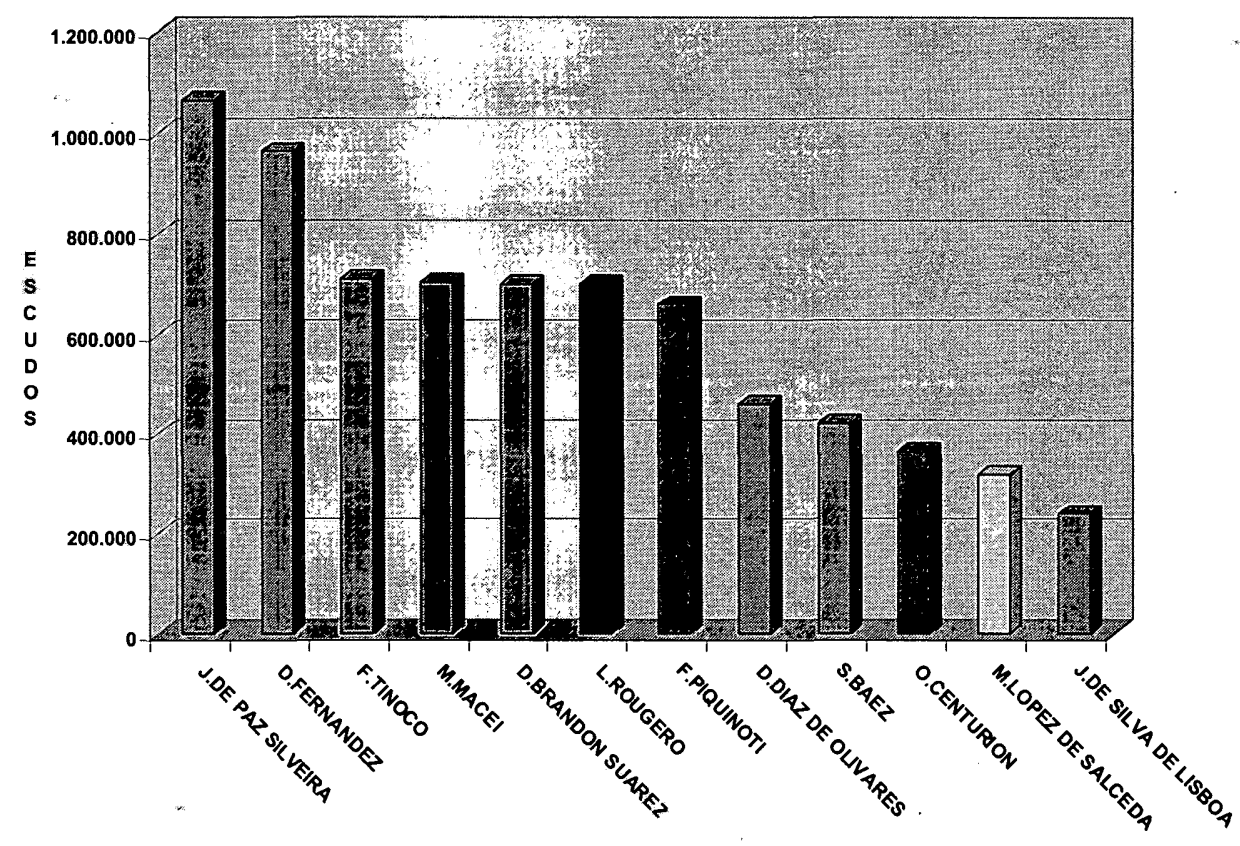

Se entiende así que en 1642 Jorge de Paz se convirtiera de modo evidente en el principal asentista de la Monarquía (Gráfico 5) ${ }^{21}$. El Monte de Piedad de Flo-

21 A.G.S. CC. GG. Leg. 137. En 1642 las provisiones generales ajustadas alcanzaron los 5.000.000 de escudos y los asentistas que se hicieron cargo de ellas fueron: Duarte Fernández: 750.000; Jorge de Paz Silveira: 1.250.000; Fernando Tinoco: 700.000; Duarte Brandón Suarez:

Hispania, LXV/1, núm. 219 (2005) 91-114 
rencia le seguía y a la zaga el genovés Alejandro Palavesín, asimilado en sus formas de negociar a los portugueses. Detrás nuevos lusos como Duarte Brandón Suarez y genoveses no tradicionales en sus métodos y alianzas como Andrea Piquinoti. Llama la atención la muy postrera posición de la casa Strata que sólo tres años antes comandaba las provisiones de asientos. La conclusión parcial es que los responsables del primer descenso del crédito global de la Monarquía, el registrado en 1641, fueron los genoveses.

\section{GRÁFICO 5: PRINCIPALES ASENTISTAS (1642)}

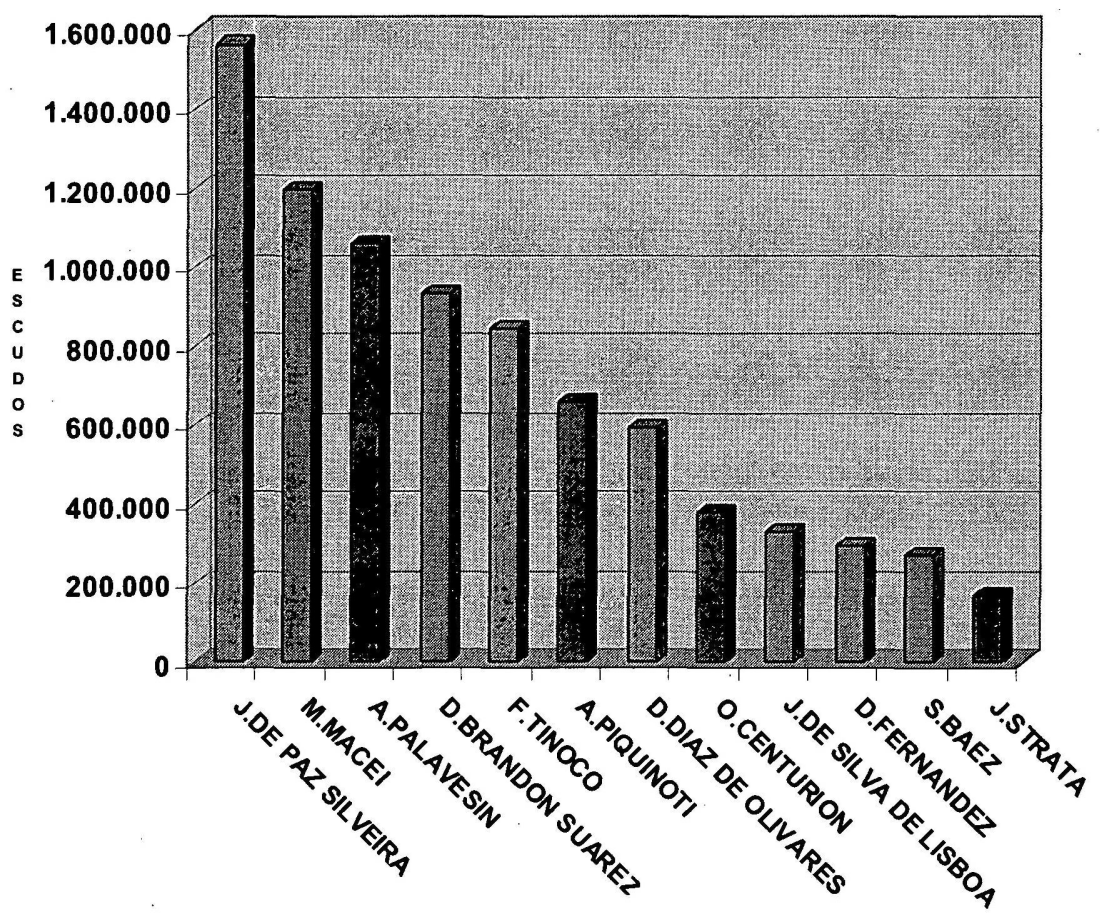

Este comportamiento del crédito genovés tradicional ofrece dos posibles lecturas que en sí no son excluyentes; una, que actuaron como siempre lo habían hecho, anteponiendo sus intereses económicos particulares a los de la Monarquía y era de esperar que en momentos de dificultades políticas y de urgencias financieras el reintegro de los préstamos y de sus intereses fuera más dificultoso siendo más prudente retirarse a un segundo plano.

800.000; Duarte Díaz de Olivares: 550.000; Juan de Silva de Lisboa: 300.000 y Andrea Piquinoti por sí y la casa de Fco. María con 750.000 .

Hispania, LXV/1, núm. 219 (2005) 91-114 
La segunda interpretación, de contenido sociopolítico, es que con su retirada parecían alinearse decididamente en contra de la facción olivarista a la que no parecían dispuestos a ayudar con sus préstamos en momentos en los que se hallaban al borde del abismo. Es curioso apreciar cómo desde el lado de la literatura panfletaria encontramos indicios que parecen avalar el alineamiento de los genoveses con los sectores sociopolíticos que defendían «el buen gobierno» frente a las innovaciones de Olivares y sus próximos. Quevedo, ya en 1628, cuando sabemos que ejercía funciones de propagandista del gobierno del Conde Duque, escribió Lince de Italia u zaborí español ${ }^{22}$, una obra en la que, entre otras cosas, ensalzaba los valores de los hombres de negocios genoveses, precisamente cuando éstos se encontraban en horas bajas tras la suspensión de 162723:

«...Cuanto importa la amistad de Génova a España, nadie lo dice mejor que lo que cuesta: asegúrala en la protección de Vuestra Majestad la discordia que tiene con Venecia, la poca seguridad de las vecindades de Francia y Saboya y acaríciala el interés que se le sigue de nuestra correspondencia que es recíproco a V.Mg. por lo puntual de los socorros tan numerosos. Mal consideran el estado de esta liga los que tienen por ruin y perniciosa su comunicación para España por el oro y la plata que sacan della. Esta es una calumnia muy grosera.

Señor, Génova a Vuestra majestad a sus reinos y ministros es de más útil que las Indias. Es Génova el cajón secreto dónde salvamos el caudal de los franceses e ingleses que lo que llevan es desaparecido y con su comercio nos dejan pobres y sucios y necios; de las Indias sólo se salvan aquellas barras que cobra Génova. Porque, aunque el oro y la plata que ellas os dan se le llevan ellos con bien regateada ganancia de tutor que esconde las joyas que ve a peligro de ser burtadas, el oro y la plata llevan a Génova, es verdad; más de allí lo pasan a emplear en posesiones, juros, rentas y estados y títulos en vuestros reinos de España, Nápoles, Milán y Sicilia. De suerte que a vuestro servicio, los más tienen bipotecados con vasallaje persona y bienes (..)»

El intento de asimilarlos en el texto con los más tradicionales intereses de la Monarquía es evidente y lo es aún más unos años después en la Execración contra los judíos, escrita en 1633, dónde Quevedo, enfrentado ya con Olivares, defiende abiertamente la gestión financiera de los genoveses identificándolos con las

22 Es una obrita escrita al parecer en 1628 (un año después de la primera suspensión de pagos del reinado) que entra en el género de los llamados «papeles». Escritos breves de motivación circunstancial con intención las más de las veces polémica que se reparten entre memoriales, libelos, epístolas y otras formas menores. Quevedo pretendía con este escrito hacerle llegar al rey su visión sobre la intervención española en la Guerra de Mantua y los peligros que corría la Corona, las intenciones de sus enemigos (Francia y Venecia) y los riesgos que se escondían detrás de sus supuestos aliados (Saboya). De paso, intenta aclarar quiénes eran los verdaderos amigos. QUEvEDO, F. de: Lince de Italia u zaborí español. Estudio preliminar y notas de Ignacio Pérez Ibáñez. Pamplona, EUNSA, 2002. p. 100.

$23 \mathrm{Y}$ criticaba de soslayo a los portugueses aún cuando en este momento se identifica con el proyecto político de Olivares. 
buenas y antiguas formas del «buen gobierno» y como única y fiable alternativa de los asentistas judeoconversos:

«...No puede ser salida destos inconvenientes decir que no hay otros con quien hacer asientos estando el caudal de la República de Génova en pié, república cristianísima y opulenta y la puntualidad y verdad de los nobles ginoveses en el propio grado que la hemos experimentado, siempre con letras verdaderas, seguras y efectivas pues con ella ban asistido hasta abora a las grandes ocurrencias del invicto Emperador Carlos $V$, vuestro bisabuelo, a las de vuestros abuelos Felipe Segundo y a las que tuvo tan apretadas vuestros santo y glorioso padre el señor Rey don Felipe Tercero (..)»24

Una apelación a un rasgo del antiguo «buen gobierno» que podía asimilarse con el resto de los que ejercían la crítica contra Olivares en otros terrenos.

Puede que esta actitud deba entenderse no sólo por el desplazamiento que sufrieron los financieros genoveses ante el empuje de los judeoconversos portugueses después de 1627, sino también por la propia evolución social que los financieros ligures más importante experimentaron en Castilla, ennobleciéndose y pasando a formar parte del círculo de intereses de la aristocracia enfrentada contra Olivares. Por ejemplo, Octavio Centurión era Marqués de Monesterio desde 1639. Formó parte al mismo tiempo del Consejo de Hacienda y del de Guerra y fue Mayordomo Mayor de la Infanta María Teresa ${ }^{25}$ y, más tarde, Tesorero de la Reina. Cumplió además una importante labor de intermediación entre la Corona y los hombres de negocios en activo procurando que sus consignaciones les llegaran a tiempo, pero en los años cuarenta se mantuvo alejado lo más posible de operaciones directas de crédito seguramente porque el tipo de compensaciones y consignaciones ofrecidas tenían una naturaleza que la nobleza tradicional no veía con buenos ojos al dañar directamente sus propios intereses.

Que los hombres de negocios genoveses recientemente ennoblecidos vincularan su imagen con los métodos financieros extraordinarios puestos en marcha por Olivares, es decir, con la de los destinatarios del beneficio del recorte de los juros, con las manipulaciones monetarias, los donativos «voluntarios», los repartimientos forzosos de deuda pública $o$, incluso, con el cobro de nuevas figuras fiscales como los Unos por ciento que perjudicaban a los detentadores de las alcabalas, -en su mayoría en manos de nobles-, no era la mejor carta de presentación para sentirse un «igual» en las filas nobiliarias que sufrían directamente los efectos de aquellas medidas.

\footnotetext{
24 Quevedo, F.de : Execración contra los judíos (1633) Ed. de F. CABO y S. Fernañdez . Barcelona, Crítica ,1996, p. 39

25 A.G.S. CC. GG. Leg. 141
}

Hispania, LXV/1, núm. 219 (2005) 91-114 
LOS GENOVESES Y LA EVOLUCIÓN DEL CRÉDITO EN LOS AÑOS INMEDIATOS A LA CAÍDA DE OLIVARES

Como señalé al principio, tras el descenso del crédito en 1641 , la siguiente caída más llamativa en el volumen de las provisiones generales negociadas durante la década se produjo en el año 1643. Convendría saber si esa caída pudo ser consecuencia de la salida del gobierno del Conde Duque y de la huída de sus financieros afines. Sabemos que las provisiones generales se negociaban en el último trimestre del año anterior, periodo en el que Olivares todavía permanecía en su puesto. Por tanto, la mayoría de los asientos de 1643 se firmaron bajo la supervisión de Olivares con el protagonismo mayoritario de financieros portugueses (Gráfico 6).

\section{GRÁFICO 6: PRINCIPALES ASENTISTAS (1643)}

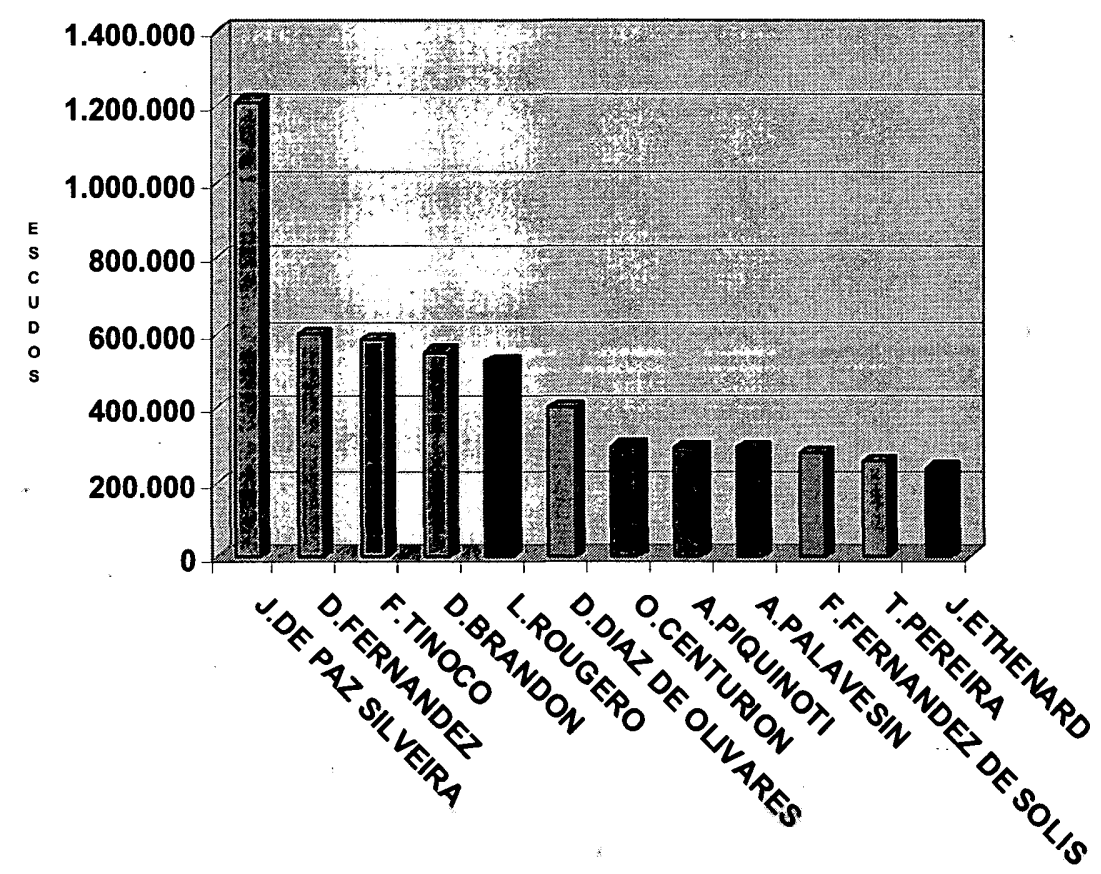

Queda saber que ocurrió después.

La destacada participación de los financieros lusos en las provisiones de 1644 y 1645 no coincide con la interpretación de que, tras la caída de Olivares, el crédito portugués se derrumbó y que, por tanto, la crisis en la oferta del crédito a partir de ese momento estaría protagonizada básicamente por el entorno «financiero» del valido caído en desgracia. Por el contrario, el crédito portu-

Hispania, LXV/1, núm. 219 (2005) 91-114 
gués hizo un esfuerzo redoblado por mantenerse y de paso por sostener las necesidades crediticias de Felipe IV en aquel difícil trance.

A lo largo de la década y hasta las inmediaciones de la suspensión de pagos de 1647, los portugueses sostuvieron su oferta global en valores que, salvo 1644, superaron los 4.000 .000 de escudos mientras los genoveses, desde 1641, redujeron su oferta manteniéndola siempre por debajo de los 2.000 .000 millones.

\section{GRÁFICO 7: PRINCIPALES ASENTISTAS (1644)}

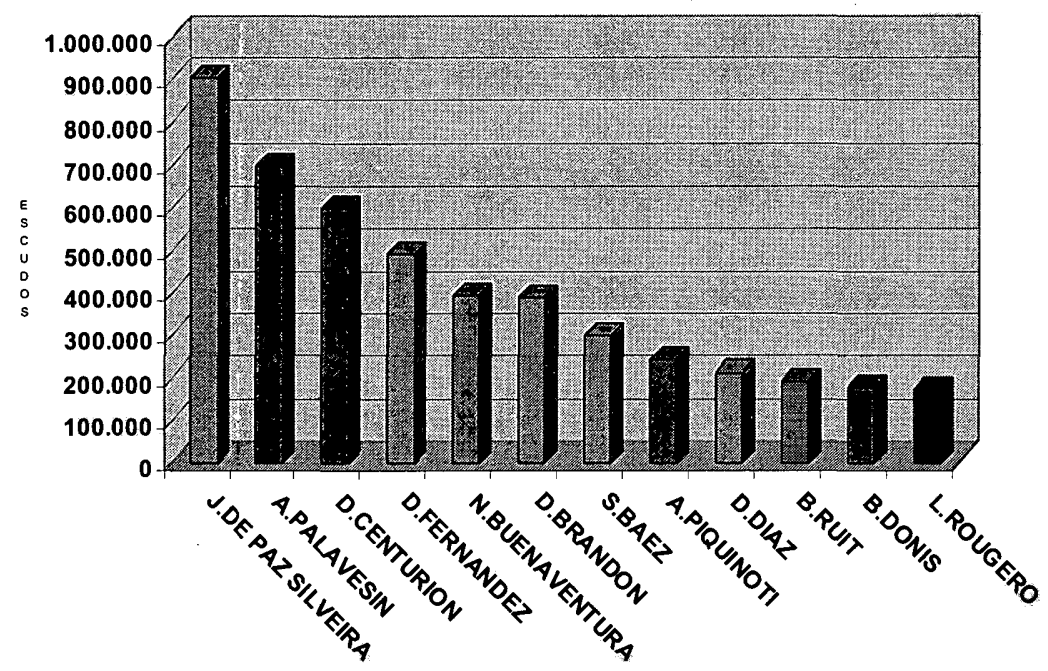

Esta tendencia se quebró a partir de 1646. El crédito negociado para ese año superó escasamente los 3.600.000 escudos contando con el vellón deflactado; la cifra más baja de toda la década y ello a pesar de que volvió a recurrirse al descuento de los réditos de juros que quedaron aprobados en febrero de aquel mismo año por el procedimiento de negociar individualmente con cada ciudad. Un descenso del crédito que, ahora sí, protagonizaron los lusos ${ }^{26}$ (Gráfico 9).

Encontrar consignaciones ese año fue la tarea más agotadora de aquella difícil década ${ }^{27}$. Sólo Jorge de Paz Silveira ocupó un lugar destacado en los asientos aunque por detrás de Juan Esteban Imbrea que trabajó con la salvaguarda de estar excluido de una posible declaración de bancarrota.

26 Pudo tener influencia también el que se produjera a fines de 1645 la primera quiebra conocida de un hombre de negocios judeoconverso Diego de Acosta, que aunque importante no era asentista de provisiones generales. Vid. Pellicer y TOBAR, J.: Avisos históricos (en Antonio VallaDARES: Semanario Erudito, y XXXII.) Madrid, 1790, p. 141-142.

27 A.M.A.E. Ms. Libs. 41, fols. 348-353. «Relación de consignaciones y efectos... Madrid, 16 de octubre de 1646. 
GRÁFICO 8: PRINCIPALES ASENTISTAS (1645)

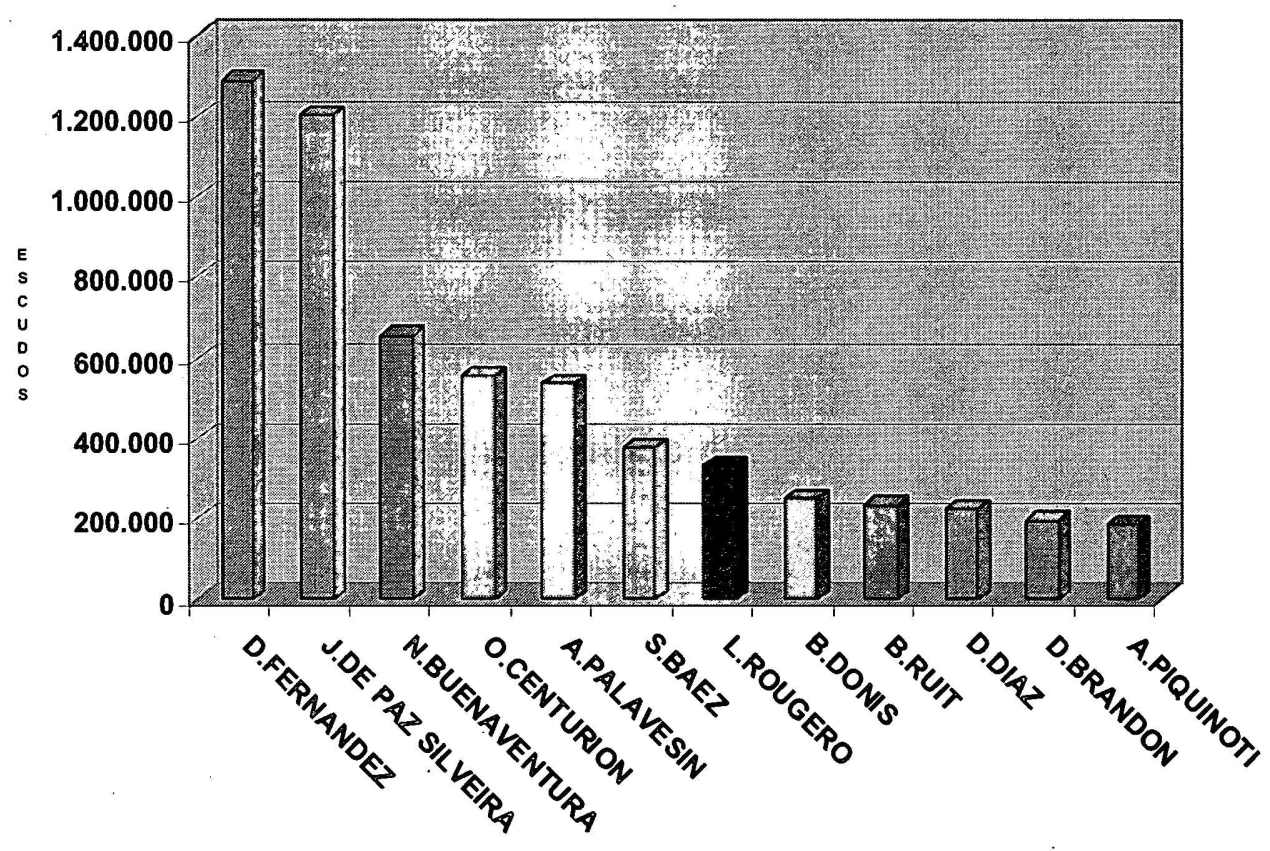

GRÁFICO 9: PRINCIPALES ASENTISTAS (1646)

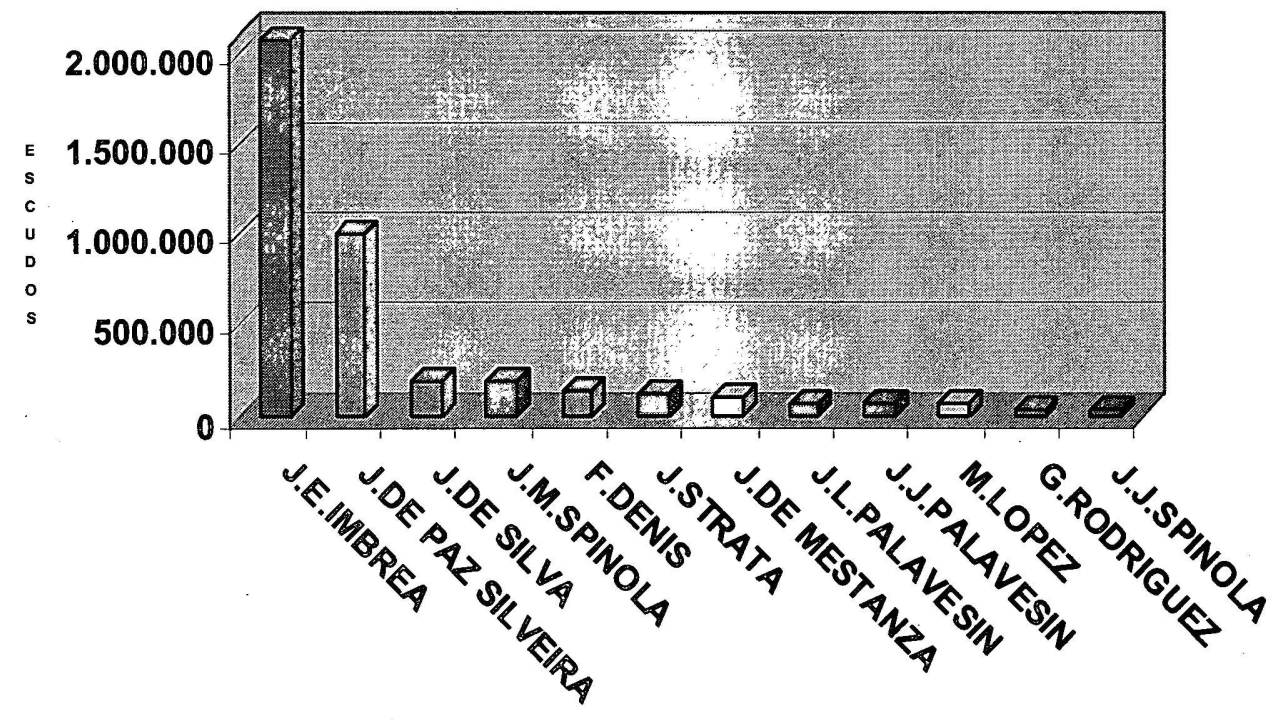

Hispania, LXV/1, núm. 219 (2005) 91-114 
Dada aquella extrema situación, en 1647 se empezó a contemplar en el Consejo de Hacienda la posibilidad de decretar una suspensión de pagos. Las crecientes dificultades para encontrar situados con los que satisfacer los asientos contratados con los hombres de negocios que hasta entonces habían colaborado con la Corona precipitó la decisión.

Sobre las razones por las que se decretó no pueden negarse causas de carácter político ya que a mediados de aquel año los frentes de guerra se ampliaron con el estallido de las sublevaciones de Nápoles y Sicilia ${ }^{28}$. Aquella situación presagiaba un mayor nivel de gasto y la Monarquía se vio obligada a replantearse el volumen de deuda flotante y sus disponibilidades. El 27 de septiembre el Consejo de Hacienda elevó al rey su parecer definitivo. La segunda suspensión de consignaciones decretada en el reinado de Felipe IV se firmó el 1 de octubre de 1647 y se justificaba por el insostenible nivel de endeudamiento que había alcanzado la Real Hacienda. No faltaba a la verdad aquel órgano colegiado en su explicación pues los asientos de provisiones generales que se habían conseguido negociar con la vista puesta en 1647 contemplaban ganancias de hasta un $78 \%$ para los asentistas ${ }^{29}$. La deuda con los banqueros alcanzaba los 13 millones de ducados de los cuales 12.900 .000 eran nominalmente en plata $^{30}$. Las rentas y servicios estaban comprometidos en muchos casos hasta 1653. Semejante situación explicaría por si sola la necesidad de la declaración.

\section{EL CRÉDITO GENOVÉS TRAS LA SUSPENSIÓN DE PAGOS DE 1647}

Una vez decidida ${ }^{31}$, la suspensión fue supervisada por el propio Don Luis de Haro. Respecto al procedimiento puesto en marcha una Junta del Decreto, - como ocurriera en anteriores ocasiones-, intentó dictaminar en discusión con los hombres de negocios la salida que se daría al impasse crediticio. Al principio la idea era de nuevo satisfacer en juros crecidos a todos los afectados, solución que necesitaba el consentimiento de las Cortes. El 6 de noviembre de 1647 se cursaba la primera solicitud para hacerlo ${ }^{32}$.

28 RiBot García, L.A.: «Las revueltas sicilianas de 1647-1648» en La Monarquía Hispánica en Crisis. Barcelona, 1992, pp. 183-199. También salieron a la luz los sucesos de la misteriosa trama del navarro Miguel de Itúrbide.

29 Pondremos como ejemplo el asiento de generales firmado por Andrea Piquinoti que prometía colocar 260.000 escudos -en Flandes la mayor parte-, equivalentes a 71.163 .664 mrvs. Las ganancias sobre el cumplimiento del asiento se cifraban en 55.994 .336 mrvs. y el reembolso completo debía ser por tanto de 126.954 .000 mrvs. Para todos los datos contables de este asiento de 1647, A.G.S. CC. GG. Leg. 141.

30 Esto en la teoría porque en la práctica muchas de ellas se convirtieron en vellón pagando los correspondientes "premios».

31 Ruiz MARTín, F.: Las finanzas de la Monarquía en tiempos de Felipe IV (1621-1665). Madrid, R.A.H. , 1990..p. 134

32 "Por consulta de la Junta del Decreto y suspensión de consignaciones de los bombres de negocios tengo resuelto se pague a los dichos hombres de negocios lo que bubieren de baber en el principal de juro de a veinte $[20.000 \mathrm{al}$

Hispania, LXV/1, núm. 219 (2005) 91-114 
Sin embargo, se exceptuó desde el principio a un grupo 33 ; los genoveses Octavio y Domingo Centurión, Jácome María Spínola, Juan Jerónimo Palavesín y Juan Esteban Imbrea ${ }^{34}$ que precisamente en 1647 había accedido al título de Conde de Yebes ${ }^{35}$ engrosando las filas de los financieros genoveses ennoblecidos.

Todos sostendrían las necesidades crediticias inmediatas mientras se firmaba el Medio General con los hombres de negocios afectados. Dado que tenían una amplia experiencia y habían estado menos implicados en los asientos de los años cuarenta, su situación económica se suponía más saneada. Asignarles ese papel era, desde un punto de vista operativo, lo más razonable ${ }^{36}$. En realidad, se excluía de la suspensión a los que teóricamente eran más capaces de realizar préstamos entre otras razones porque, en los últimos años, habían suministrado menos. Desde la administración de hacienda se pensó además que lo harían gustosos y con un espíritu de cierta revancha hacia los portugueses que se habían convertido en sus principales competidores en el mercado de capitales desde los años veinte:

«...sin que la novedad del decreto lo impida porque por sí y sus correspondientes no tienen dependencia con los portugueses, antes son aborrecidos de los genoveses» 37 .

Los miembros del Consejo de Hacienda que hacían estos juicios demostraban cierto desconocimiento de la realidad financiera que les rodeaba. Hablar de los genoveses como un solo bloque era un error. Tener el mismo origen nacional no significaba que tuvieran los mismos intereses. Hoy sabemos que la entente entre los lusos y algunos ligures, - los más activos por estos años-, funcionó no sólo a partir de $1650^{38}$ como lo corroboraron varias provisiones firmadas conjuntamente por las firmas Cortizos-Piquinoti a partir de esa fecha $^{39}$; estas asociaciones se dieron antes.

millar es decir 5\%] contados a su entero precio en plata (...). Hareis que luego se saque este consentimiento del Reyno en la conformidad que queda dicha»A.H.N. Consejos. Leg. 13.202 (111) 6 de noviembre de 1647.

33 Este era un procedimiento común en todos las suspensiones de pagos pues era un modo de garantizar unas provisiones mínimas hasta tanto se solucionaban, con el resto de financieros, las cuentas de los asientos afectados.

34 Dominguez Ortiz, A.: Política y Hacienda...cit. p. 97

35 Ya se le designa con este título en las provisiones generales firmadas en 1647. A.G.S. CC. GG. leg. 141

36 Había ocurrido algo parecido cuando se excluyó a los Fugger en suspensiones anteriores. Parecían estar retirados del negocio directo de asientos auque su capacidad financiera como gestores de las minas de Almadén era una garantía para la Real Hacienda. Por tanto el gesto no era demasiado nuevo.

37 A.G.S. C.J.H leg. 907, Junta sobre Medios 27-IX- 1647.

38 SANZ AYÁN, C.: «El crédito de la Corona y los hombres de negocios en los últimos años del reinado de Felipe IV» Cuadernos de Historia Moderna, $\mathrm{n}^{\circ}$ 9, 1988, pp. 63-94.

39 SANZ AYÁn, C.: Los banqueros de Carlos II. Universidad de Valladolid, Salamanca, 1988, pp. 179-180.

Hispania, LXV/1, núm. 219 (2005) 91-114 
El caso de Alonso y Diego Cardoso, asentistas de la Armada en los años treinta resulta ejemplar. Alonso Cardoso tenía una estrecha relación con los Palavesín de Génova. Su procurador en aquella ciudad era Paolo Gerolamo Pallavicino el sobrino del factor genovés en Madrid, Juan Lucas. Una parte muy importante de los metales preciosos que los Cardoso recibieron en Sevilla, salieron en galeras hacia Génova para ser depositados en la casa de los Pallavicino que después se encargaban de venderlos al mejor postor en la propia ciu$\mathrm{dad}^{40}$. También Jorge de $\mathrm{Paz}$ Silveira tenía esta conexión «italiana». Al menos hacía grandes transferencias de dinero a través del Puerto de Barcelona junto a los hombres de negocios genoveses. Por último, el asentista converso García de Illán, tras su abandono de la Península por denuncias de la Inquisición, se instaló primero en Italia y luego en Amberes dónde siguió atendiendo los compromisos crediticios no sólo de Duarte Fernández sino también de Alejandro Palavesín ${ }^{41}$. Tanto la casa Piquinoti como la rama secundaria de los Palavesín no tuvieron escrúpulo alguno en «mezclarse» con negocios y asentistas portugueses. Recibían consignaciones de naturaleza similar y entraron en los mismos repartos y sorteos.

En 1648 los contratos más urgentes de crédito se ajustaron precisamente con los genoveses tradicionales. Aquellos que habían mostrado una actitud más retraída durante la década, se comprometían ahora a realizar las provisiones por vía de factoría y no por asiento (Gráfico 10), es decir, como teóricos adminis-

\section{GRÁFICO 10: PRINCIPALES HOMBRES DE NEGOCIOS (1648)}

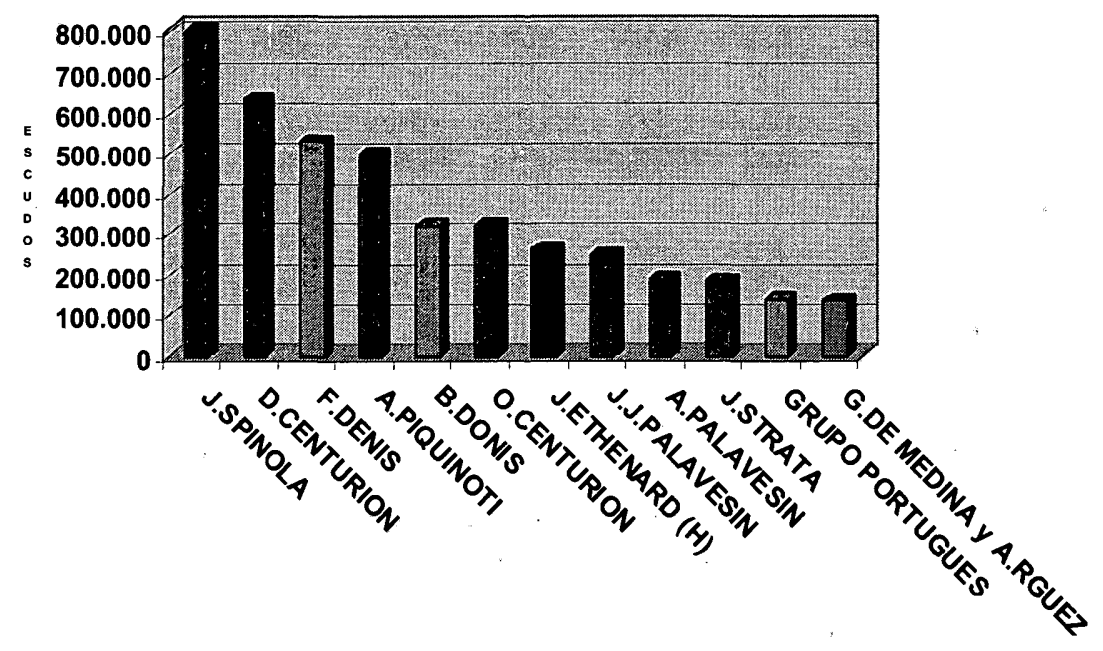

40 Alvarez Nogal, C.: El crédito de la Monarquía...cit., p. 106

41 BRoENS, N.: Monarquía y capital mercantil. Felipe IV y las redes comerciales portuguesas (16271635) . Madrid, UAM, 1989. p. 64 
tradores de la Real Hacienda y no como verdaderos asentistas. Sin embargo, a estas operaciones de crédito firmadas en 1648 sólo les quedaba de factorías el nombre. Ni los intereses se moderaron ni el título de factor supuso para los hombres de negocios que las asumieron una salvaguarda para no verse afectados por posteriores suspensiones de pagos.

Que el Consejo de Hacienda y Don Luis de Haro apelaran a los servicios de los genoveses tradicionales en 1648 pudo ser no sólo un recurso económico, sino un gesto político que evidenciara la definitiva vuelta al buen gobierno tras la gestión de Olivares y los años inmediatamente posteriores en lo que se mantuvieron sus colaboradores financieros y sus métodos, aún sin su presencia.

Tras la suspensión, los factores genoveses suministraron a lo largo del año 2.453 .187 escudos de plata y 572.479 en vellón ${ }^{42}$. Cantidades que resultaron del todo insuficientes dadas las necesidades a las que había que hacer frente. Lo mínimo que se necesitaba para cumplir con las provisiones exteriores en 1648 eran entre 3.500 .000 y 4.000 .000 de ducados y los hombres de negocios genoveses constituidos en factores no llegaron a esta cifra. Junto a José Strata, Jacome Spinola y Octavio Centurión hubo que acudir a las impertérritas casas «contaminadas» por su relación con portugueses de Andrea Piquinoti y Alejandro Palavesín que ahora tenía el testigo del establecimiento de los Imbrea que al principio se encontraban también en la lista de decretados.

Esta falta de capacidad crediticia de los genoveses tradicionales pudo deberse a varias causas pero seguramente la más decisiva fue la naturaleza de las consignaciones que la Real Hacienda ofreció como reembolso por sus contratos. Aquellas consignaciones no supusieron nada excepcional respecto a los reembolsos de los años inmediatamente anteriores y, desde luego, no eran lo que podía esperar un factor tradicional: ingresos seguros y de rápido ingreso.

Entre las libranzas que se encontraron los factores de 1648 había, por ejemplo, nuevas contribuciones eclesiásticas. Conviene detenerse un momento en la consecución de una de estas rentas para hacernos una idea precisa de cual era el estado del crédito y de los conceptos fiscales que lo sustentaron entre

42 A.G.S. CC. GG. Leg. 142. El desglose pormenorizado de estas factorías de italianos fue el siguiente:

ANDREA Piquinoti: 327,500 Esc. De plata. Y 175.500 Esc. De vellón

DOMIngo Centurión. 571.448 Esc. De plata y 95. Esc. De vellón

JuAN Jerónimo PALAVESín: 250.000 Esc. De plata

JOSEPH STRATA: $152 . .333$ Esc. De plata y 67.666 Esc. De vellón

JACOME SPÍNOLA: 700.000 Esc. De plata y 150.000 Esc. De vellón

OCtAvio Centurión. 288.100 Esc. De plata y 47.620 Esc. De vellón.

Debe advertirse que Piquinoti y Strata, no pertenecían al primer grupo de factores excluidos del decreto. Ellos como genoveses nuevos, habían sido menos escrupulosos a la hora de mezclarse en las negociaciones de años anteriores, con los financieros portugueses y quizá por ello, fueron decretados también en la primitiva lista de afectados de octubre de 1647 aunque consiguieron ser los primeros en salir de ella.

Hispania, LXV/1, núm. 219 (2005) 91-114 
1647 y 1648. En septiembre de 1647, un mes antes de la suspensión, Felipe IV encargaba al Conde de Oñate, embajador en Roma desde el otoño de $1646^{43}$, la petición de una décima de 800.000 ducados en razón de:

«lo mucho que falta para poder disponer las provisiones generales ordinarias y extraordinarias del año que viene de $1648{ }^{44}$.

La diligencia tuvo su efecto y en diciembre de ese año Inocencio X concedió un nuevo subsidio extraordinario sobre las rentas de los reinos de Castilla y León pagadero, en principio, en dos anualidades. Aquella gracia provocó una gran oposición entre el clero sobre todo porque los cardenales estaban exentos de pagarla. Se negoció con el estamento y al final se llegó a un acuerdo sobre la cantidad final que abonarían: 550.000 ducados pagaderos en cuatro años mediante ocho pagas; los cardenales finalmente, también contribuirían. La escritura de concordia se otorgó el 7 de junio de 1649 aunque la ansiada licencia pontificia para que los cardenales contribuyesen no se consiguió con lo que el producto neto de la décima apenas llegó a 300.000 ducados $^{45}$. Es el ejemplo típico de los avatares que sufrían las consignaciones de los hombres de negocios tanto antes como después de la suspensión de pagos. Ingreso calculado en 800.000 ducados pagadero en dos años que primero se redujo a 550.000 ducados y luego a 300.000 y con una dilación en su cobranza de cuatro años; el doble de lo previsto.

Esta nueva renta estaba prometida a los factores excluidos del decreto de suspensión de pagos desde enero de 1648, un año antes de que comenzara a materializarse. Como los cálculos de las consignaciones se hicieron sobre los 800.000 ducados iniciales, reducidos luego en la contabilidad a 550.400 ducados, el Consejo de Hacienda repartió libranzas durante 1648 por el importe teórico; libranzas que quedaron en papel mojado ${ }^{46}$ ya que los hombres de negocios no las cobraron ni en su totalidad ni a tiempo. La nueva etapa de las finanzas de la Monarquía no empezaba mejor de lo que había terminado la antigua. Los compromisos firmados por los hombres de negocios genoveses rescatados para las nuevas negociaciones podían llamarse factorías, pero las con-

43 La elección de Inocencio X Pamphili en 1644 inició un proceso de reconstrucción de la facción española en Roma descrito someramente por DANDELET, T.J.: La Roma española (1500-1700). Barcelona, Crítica, 2002, p. 249 y ss. En el que se enmarca la concesión sin demasiadas dificultades del servicio aludido.

44 A.H.N. Consejos lib. 23 fol. 70 citado en: CARPINTERO AGUADO, L.: «Las décimas eclesiásticas en el siglo XVII: Un subsidio extraordinario» en FeRnÁnDEZ AlbaladejO, P. (Ed.): Monarquía, Imperio y pueblos en la Edad Moderna. Universidad de Alicante .A.E.H.M. Alicante, 1997 pp. 747-756. En concreto, p. 751

45 A.H.N. Consejos lib. 24, fol. 185

46 -El Marqués de Monesterio (Centurión) : 21448386 mrvs. -Juan Jerónimo Palavesín: 9252500 mrvs.

-Alejandro Palavesín: 9160326 mrvs.

-Conde de Yebes (Imbrea): 166.996.288 mrrvs. 
signaciones obtenidas reflejaban los mismos riesgos que asumieron los asentistas de provisiones generales en años anteriores.

Cualquier intento de «semi» gestión del crédito a través de las llamadas factorías después de la suspensión fue un fracaso, porque la naturaleza de los ingresos que la Monarquía manejaba poco tenían que ver con aquel histórico concepto de factor cuya principal labor consistía en cambiar de sitio o a lo sumo adelantar, durante un muy corto espacio de tiempo, sumas de dinero que la Real Hacienda había ingresado con certeza.

La naturaleza de las consignaciones ofrecidas a los hombres de negocios en 1648 implicaban necesariamente la acción de profesionales de las finanzas que adelantaran el dinero y tuvieran un interés propio a la hora de cobrar de manera efectiva el producto de impuestos y servicios cada vez más complicados en su gestión. No valían aspirantes a funcionarios. Hacer aquel trabajo tenía un precio elevado; más caro incluso que lo que cobraron los hombres de negocios activos en plena década de los cuarenta: aquellas factorías firmadas por negociantes vinculados al capital genovés tradicional, superaron siempre el 55\% de interés global ${ }^{47}$.

La explicación de estos altos intereses no puede ser sólo que los genoveses intuían que las consignaciones ofrecidas por la Monarquía eran exiguas ${ }^{48}$; lo más importante quizá era que no diferían cualitativamente de las que los hombres de negocios de provisiones generales habían recibido en los años anteriores. Creo que esa era la clave: que no se diferenciaban en nada ${ }^{49}$ y su naturaleza no atraía a los financieros genoveses tradicionales por varios motivos, no todos ellos de naturaleza económica. Salvo lo calculado en plata de galeones que finalmente no se cumplió, esos reembolsos se sustentaban en medias anatas de juros, en monopolios como salinas y papel sellado y, sobre todo, casi un $40 \%$ en Millones y Quiebras de Millones; unos servicios que, con ser los más importantes de la Real Hacienda en volumen, presentaban dificultades en el momento de hacerse efectivos por los impedimentos que esgrimieron las autoridades locales plenamente implicadas en los procesos de cobranza tal y como se había demostrado en los años inmediatamente anteriores.

47 Que los genoveses eran en general más «caros» a la hora de proporcionar crédito incluso antes de la suspensión lo insinúa Quevedo en la Execración (1633) cuando dice: «No es buena conveniencia escoger por menos intereses en los conciertos a los judíos conversos porque en el trato no es menos costoso el que pide menos y se queda con todo que aquellos que en el asiento piden más y no faltan en nada. Nadie regatea menos en lo que trata que el embustero que sabe que no ha de cumplir lo que ofrece.» QUEVEDO, F.de : Execración contra los judíos (1633) Ed. de F. CABO y S. FERNANDEZ . Barcelona, Crítica ,1996, p. 40.

48 Todo indica que en el Consejo de Hacienda se pensaba que las disponibilidades de estos históricos genoveses eran mayores, pues en la valoración que hace de ellos Bartolomé de Legasa se dice que tras el decreto, el presidente de Hacienda: «..estaba en firme resolución de no admitir a ningún portugués para la negociación, tratando de haber caudal, — que era muy grande-, con los genoveses, en quienes se experimentaba gran diferencia en la puntualidad y verdad de sus provisiones.» En A.G.S. Estado. leg. 2668.

49 A.G.S. CC. GG. leg. 142

Hispania, LXV/1, núm. 219 (2005) 91-114 
Comparando las consignaciones de Jacome $\mathrm{M}^{\mathrm{a}}$ Spinola y las de Alejandro Palavesín, (Tabla I) podremos darnos cuenta en primer lugar de que la Monarquía operó con los factores como con los asentistas de generales. Había unas consignaciones que repartirse y se adjudicaron proporcionalmente. La Monarquía no podía "crear» reembolsos más atractivos. Sólo podía distribuir los que había y si conseguía otros nuevos conceptos fiscales éstos eran de parecida naturaleza a los anteriores.

\section{TABLA I}

\begin{tabular}{|l|c|c|}
\hline CONSIGNACIONES 1648 & $\begin{array}{c}\text { JÁCOME MARÍA } \\
\text { SPÍNOLA }\end{array}$ & $\begin{array}{c}\text { ALEJANDRO } \\
\text { PALAVESín }\end{array}$ \\
\hline Plata de Galeones & $10,92 \%$ & $11,25 \%$ \\
\hline Plata en la Corte & $2,93 \%$ & $2,95 \%$ \\
\hline $2^{\circ}$ Derecho de la Media Anata & $5,86 \%$ & - \\
\hline Vellón en la Corte & - & $5,9 \%$ \\
\hline Millones de 1648 y 1649 & $29,8 \%$ & $29,6 \%$ \\
\hline Papel Sellado & $8 \%$ & $8 \%$ \\
\hline $2^{\circ}$ Uno por ciento de lo vendible & $5,13 \%$ & $5,1 \%$ \\
\hline $\begin{array}{l}\text { Servicio de los 2 Millones y medio de } \\
1648 \text { y 1649 }\end{array}$ & $13 \%$ & $12,94 \%$ \\
\hline Quiebras de Millones & $9,24 \%$ & $9,2 \%$ \\
\hline Rentas de Salinas & $5,84 \%$ & $5,8 \%$ \\
\hline Excusado & $4,96 \%$ & $4,96 \%$ \\
\hline Imposición del Real por fanega de Sal & $4,32 \%$ & $4,3 \%$ \\
\hline
\end{tabular}

La consecuencia fue que el crédito genovés tradicional sólo estuvo dispuesto a entrar con amplísimo margen de ganancia en el «juego» financiero. Si la Real Hacienda pretendía que ellos sostuvieran el crédito a intereses moderados tras la suspensión, desde luego no lo habían conseguido con estos contratos. Es posible que algunos miembros del consejo de Hacienda plantearan la bancarrota como una "cantonada» a los portugueses y un «ofrecimiento» monopolístico del negocio crediticio a los tradicionales genoveses asimilados ahora con los tradicionales usos del «buen gobierno» anterior a Olivares. En este sentido, se ${ }^{50}$ han aportado testimonios que parecen estar en el camino de probar la intención de quebrantar a los financieros lusos de modo particular con la suspensión de pagos, implicados hasta el final con el régimen olivarista. Por ejemplo el 27 de septiembre de 1647 la Junta de Medios afirmaba que la medida era necesaria para defenderse de los hombres de negocios que habían «tiranizado» al mo-

so Valladares, R.: La rebelión de Portugal 1640-1680. Valladolid, 1998, p. 69 
narca sirviéndose de sus necesidades ${ }^{51}$ y abundando en esta opinión el presidente del consejo de Hacienda buscaba:

«.. hallar algún medio honesto con que echar de Castilla a esta nación, considerándola por la más perniciosa y enemiga, así por lo que se recela de que abusan algunos de nuestra sagrada religión y lo que cada día se ve, como por su poca verdad y tratos ilícitos de que usan»s2.

Pero de la intención al hecho medió la fuerza de la necesidad. La Real Hacienda debió suplir lo que no cubrieron los factores genoveses elegidos acudiendo a otros hombres de negocios incluidos al principio en la suspensión y que, como compensación para hacer nuevos asientos, exigieron salir de la lista de decretados. El Monte de Piedad de Florencia, Joseph Strata y Andrea Piquinoti lo hicieron como factores; y después una larga lista de hombres de negocios de origen portugués: la casa de Jorge de Paz Silveira, la de Manuel de Paz, Fernando Tinoco, o Bentura Donis ${ }^{53}$ de modo que de los más de sesenta hombres de negocios afectados por el decreto tan sólo una quincena no pudieron zafarse de él ${ }^{4} 4 \mathrm{y}$ entre ellos no estaban desde luego los más importantes.

La oferta lanzada por el consejo de Hacienda a los genoveses tradicionales después de la suspensión, no tuvo la solidez y los márgenes de ganancia de las operaciones que los ligures protagonizaron en la primera mitad del siglo XVII y se explica así que hubiera que acudir rápidamente al crédito luso, fuera éste experimentado o advenedizo, porque los genoveses tradicionales, con una actitud llena de reparos por causas económicas pero también de origen sociopolítico, no estaban dispuestos a ser los exclusivos sostenedores del maltrecho crédito de la Corona.

En 1649 los niveles de crédito no se recuperaron (Gráfico 11). La Monarquía sólo consiguió firmar asientos por valor de poco más de 4.400 .000 escudos. La apuesta de la Real Hacienda por el crédito genovés resultó un fracaso. Ninguno de los hombres de negocios de aquella nacionalidad excluidos de la suspensión al principio adoptó el papel de líder en las operaciones de crédito y el concurso de los «nuevos portugueses» se hizo necesario. De hecho, la presencia de unos y otros se equilibró a partir del último año de aquella década; entre los genoveses

51 A.G.S. C.J.H. leg. 907.

52 A.G.S. Estado, leg. 2668. Bartolomé de Legasa a D. Fernando Ruiz de Contreras 20 de septiembre de 1648 .

53 Para la trayectoria negociadora de su casa a lo largo del siglo XVII vid.. SANZ AYÁN, C.: «Blasones son escudos». El ascenso económico y social de un asentista del rey en el siglo XVII, Bentura Donis» Cuadernos de Historia Moderna n 20, 1998, pp. 33-57

54 La lista original de decretados es muy amplia; la incluye Dominguez OrTiz, A.:, Politica y Hacienda...cit. p. 97. Emanada de A.G.S. CC. GG. Leg. 1725. A ella RUIZ MARTín, F.: Las finanzas de la Monarquía...cit., p. 136, añadió siete nombres más de cargadores de Indias que también se vieron afectados por el decreto.

Hispania, LXV/1, núm. 219 (2005) 91-114 
encontramos a Domingo Centurión, Andrea Piquinoti o Jacome María Espínola. Entre los portugueses a Felipe Denis, Ventura Donis o Manuel Cortizos.

\section{GRÁFICO 11: PRINCIPALES HOMBRES DE NEGOCIOS (1649)}

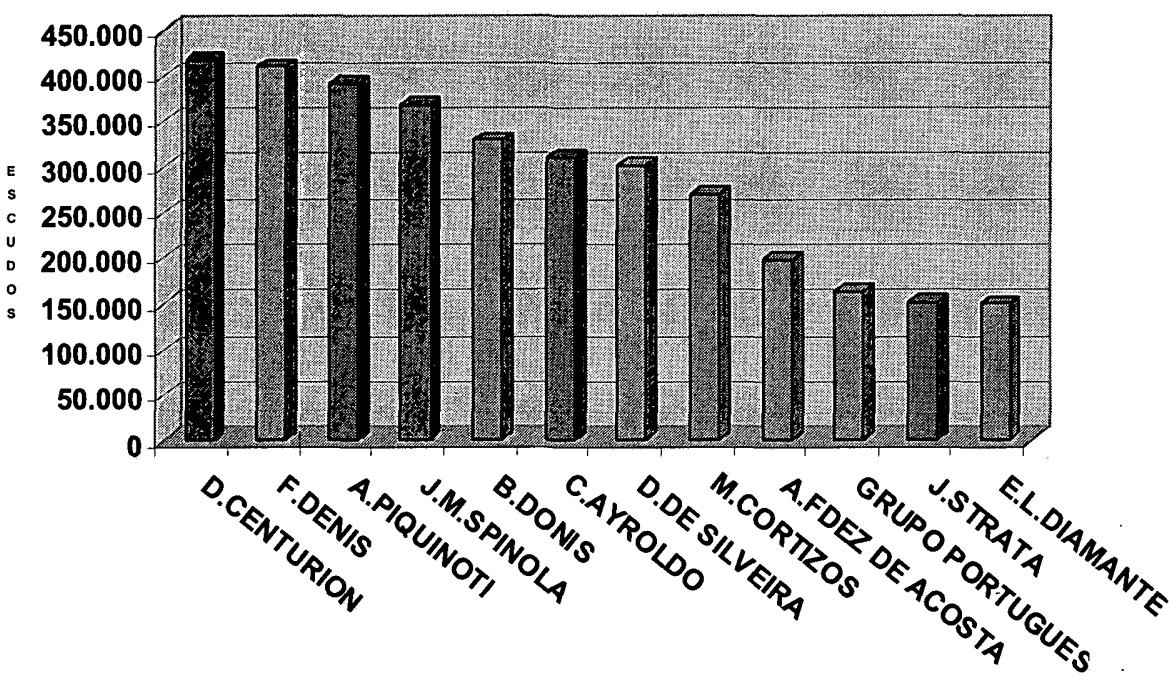

Todos adoptaron el sistema de negociación por factoría y esta nomenclatura en la negociación del crédito terminó por generalizarse en los primeros años de la década de los cincuenta, seguramente en un intento por dignificar la actividad de los profesionales del crédito que preferían ser tratados como agentes de la Monarquía y no como vulgares prestamistas. Las factorías en ese tiempo no significaron mucho más que un cambio en el tratamiento nominal del hombre de negocios.

En definitiva, el crédito tradicional genovés durante los años cuarenta vivió un periodo de retraimiento y retroceso, influido por las difíciles circunstancias económicas y seguramente también por la falta de implicación en el programa político de Olivares durante los últimos años del valimiento. Su retirada pudo ayudar al sector político de oposición que propició la caída del valido. Sin embargo, tras la desaparición del Conde Duque, los genoveses tradicionales sólo tuvieron un efímero papel protagonista después de la suspensión de pagos de 1647. La naturaleza de las compensaciones ofrecidas por la Monarquía, que eran muy distintas en su calidad de las que les hicieron ocupar un puesto de vanguardia en las operaciones de crédito de los dos anteriores reinados, invitaron a los ligures a adoptar una actitud tímida e insuficiente en sus ofertas de provisiones. El concurso de los hombres de negocios portugueses en esta situación de déficit se hizo absolutamente necesario y si en algún momento existió 
una pugna entre ambos grupos financieros, el fin del conflicto entre la Monarquía Hispánica y las Provincias Unidas- además de la conclusión de la Guerra de los Treinta Años en Europa- deben considerarse motivos de peso para que algunas firmas, las más flexibles en su operativa (Piquinoti, Grillo, Lomelín), optaran por trabajar en colaboración y no en competencia con los portugueses, a partir de 1650 . 